\title{
¿Constitucionalizar el derecho o politizar la Constitución? Amenazas, riesgos y peligros en el constitucionalismo contemporáneo
}

\author{
Constitutionalize the law or politicize the \\ Constitution? Threats, risks and dangers in \\ contemporary constitutionalism
}

\section{EDUARDO HERNANDO NIETO*}

Resumen: Desde inicios de la modernidad se ha venido imponiendo el empleo de la retórica, es decir, la técnica de pervertir el lenguaje dotando a los conceptos de distintos significados para presumir que nada ha cambiado cuando en realidad sí se ha dado el cambio. Esto mismo acontece con el concepto de Constitución, que ha modificado completamente su sentido a partir del avance de la moral de los derechos individuales. Este texto pretende mostrar la naturaleza de este cambio y reivindicar a su vez la vigencia del «viejo constitucionalismo» y el imperio de la ley y la decisión política a partir de una lectura crítica del constitucionalismo contemporáneo y su tendencia a constitucionalizar o materializar el derecho, contribuyendo paradójicamente a poner en riesgo los valores que pretende defender.

Palabras clave: constitucionalismo contemporáneo - constitucionalismo clásico - valores liberales y democráticos

Abstract: Since the beginning of modernity, the use of rhetoric have prevailed; that is, the technique of perverting the language giving concepts different meanings presuming nothing have changed when in fact, it has occurred. The same thing happens with the concept of Constitution, it has been completely modified its sense from the progress of individual rights moral. In this article the intention is to demonstrate the nature of this change and at the same time claim on the «old constitutionalism» validity and also the rule of law and political will beginning on a critical reading of contemporary constitutionalism and considering its tendency to constitutionalize or materialize the law, ironically risking the same values intended to defend.

Key words: contemporary constitutionalism - classic constitutionalism liberal and democratic values

* Doctor en Filosofía por la Universidad Nacional Mayor de San Marcos, máster en Teoría Social y Política por la Universidad de East Anglia (Inglaterra). Profesor ordinario del Departamento de Derecho de la PUCP. Profesor en el Postgrado de Derecho de la PUCP, la UNMSM, USMP, y en el pregrado de la UPC. Profesor y consultor de la Academia de la Magistratura. Consultor del PMSJ, Banco Mundial. Correo electrónico: ehernan @ pucp.edu.pe 
CONTENIDO: I. ¿QUÉ ES EL CONSTITUCIONALISMO CONTEMPORÁNEO?.II. EL CONSTITUCIONALISMO CLÁSICO: EL LIBERALISMO Y LA VIRTUD.III. LA MORALIZACIÓN DE LA CONSTITUCIÓN Y LA AMENAZA A LOS VALORES LIBERALES Y DEMOCRÁTICOS.- VI. CONCLUSIONES.

\section{I. ¿QUÉ ES EL CONSTITUCIONALISMO CONTEMPORÁNEO?}

Hace ya algunos años que los conceptos «Constitución», «constitucionalismo» ${ }^{1} \mathrm{y}$ «constitucionalización» vienen siendo difundidos con amplitud en los medios académicos y en el lenguaje de los operadores del derecho. Evidentemente, constitucionalismo y Constitución no son términos nuevos; sin embargo, la novedad radica en lo que estos significan hoy en día, y también respecto del agregado «constitucionalización». Como señala un texto reciente dentro del debate ya iniciado: «la constitucionalización no es sino un proceso mediante el cual se viene reconfigurando la teoría política del constitucionalismo»² ${ }^{2}$.

Pero, ien qué se sustenta dicho cambio en el constitucionalismo y qué va a generar la actual constitucionalización?: «el constitucionalismo ya no es tratado más como una evocativa pero vaga teoría que expresa una creencia en la importancia de un gobierno limitado y que rinda cuentas y aplicable a circunstancias particulares de ciertos regímenes. Ahora se presenta como una metateoría que establece los estándares autoritativos de legitimidad para el ejercicio del poder público dondequiera que se encuentre este» ${ }^{3}$. En este sentido, y complementando el párrafo anterior, se puede señalar que «la constitucionalización se refiere al proceso por el cual un creciente margen de la vida pública está sujeto a la disciplina de las normas del constitucionalismo legal-liberal $»^{4}$. De esta manera, la Constitución contiene una serie de reglas, pero que tienen un sustrato de principios — de raíz liberal, obviamente- que son los que prescriben los criterios para poder justificar una acción o conducta 5 .

Por otro lado, según el conocido texto del profesor Paolo Comanducci ${ }^{6}$ - siguiendo el mismo sentido del razonamiento propuesto por Norberto Bobbio en el siglo pasado ${ }^{7}$ respecto del positivismo-, el constitucionalismo podía ser considerado también como una teoría

1 El constitucionalismo no es sino una teoría política que se genera a partir del desarrollo de la filosofía liberal destinada a moldear las constituciones modernas, sustentadas básicamente en la tesis del gobierno limitado y la garantía de iguales derechos para todos.

2 LOUGHLIN, Martin. "What is Constitutionalism?». En Petra DoBNER y Martin LoughLIN (eds.), The Twilight of Constitutionalism. Oxford: Oxford University Press, 2010, p. 60.

3 lbíd.

4 Ibíd., pp. 60-61.

5 Como señala un conocido constitucionalista contemporáneo, Gustavo ZAGREBELSKY. En El derecho dúctil, ley, derechos, justicia. Madrid: Trotta, 1999, p. 110.

6 ComANDUCCI, Paolo. "Formas de (neo)constitucionalismo: un análisis metateórico». En Miguel CARBonell (ed.), Neoconstitucionalismo(s). Madrid: Trotta, 2005.

7 Bоввı, Norberto. El problema del positivismo jurídico. México: Fontamara, 2009. 
del derecho, un método para abordar el estudio del derecho o finalmente una ideología del derecho.

Sin duda, se trata este de un concepto bastante discutido en la teoría del derecho de la actualidad, y de alguna forma encarna también una nueva forma de teoría del derecho - como veremos más adelanteque, según se ha señalado, correspondería a una teoría no positivista o postpositivista del derecho ${ }^{8}$. Esta teoría centra su existencia en la moral de los derechos individuales a partir precisamente de la afirmación de que entre el derecho y la moral existe una conexión necesaria y permanente?

Precisamente, dada esta conexión necesaria y permanente entre el derecho y la mora ${ }^{10}$, muchos académicos y no académicos podrían pensar más bien que el constitucionalismo sería la mejor concepción del derecho posible, pues de esta forma el derecho podría exhibir, ahora sí, un fuerte compromiso con los valores, la justicia, la libertad y la democracia, cosa que si bien podría decirse también del constitucionalismo anterior —e incluso del propio derecho positivo ${ }^{11}$ —, sin embargo, nunca alcanzó el grado de compromiso y relevancia que hoy se da en esta teoría.

Precisamente el interés de mi trabajo radica en mostrar cómo se ha venido dando ese giro del constitucionalismo clásico - llamémoslo asíhacia el neoconstitucionalismo o constitucionalismo contemporáneo, y cómo es que se produce el fenómeno de la constitucionalización. Finalmente, cuál sería el impacto de la constitucionalización en la salvaguarda de los valores liberales y democráticos que pretende defender, pues paradójicamente considero que esta tendencia no servirá para su defensa.

Retomando lo expuesto por Comanducci, entonces, al hablar de la teoría constitucional contemporánea (también llamada neoconstitucionalismo) se está refiriendo a una teoría del derecho que busca mostrar el cambio que genera la constitucionalización del derecho. Ahora bien, dicha

8 ATIENZA, Manuel y Juan RUIz MANERO. «Dejemos atrás el positivismo jurídico». En Para una teoría postpositivista del Derecho. Lima/Bogotá: Palestra/Temis, 2009.

9 Ciertamente sobre este punto los filósofos analíticos del derecho plantearán matices interesantes, pues también podrían referirse a posiciones intermedias en el sentido de considerar que pueda haber una conexión contingente entre el derecho y la moral, y de esta manera, cabría hablar de una teoría constitucionalista que no fuese incompatible con el positivismo metodológico.

10 Precisamente hace muy poco (el 14 de febrero) ha fallecido uno de los principales teóricos que abonaron en favor de esta suerte de naturaleza moral del derecho: el profesor Ronald DWORKIN (1931-2013). Ver sus textos: Los derechos en serio. Barcelona: Ariel, 1984; El imperio de la justicia. Barcelona: Gedisa, 1988; La justicia con toga. Madrid: Marcial Pons, 2007, y su último libro, Justice for Hedgehogs. Cambridge, MA: Harvard University Press, 2011. Según lo sostenido por Comanducci, el profesor Dworkin habría sido uno de los principales exponentes del llamado constitucionalismo ideológico (COMANDUCCl. Ob. cit., p. 86).

11 Recordemos que en el esquema kelseniano, si bien el sistema normativo era formal, la obligación de obedecer las reglas por parte de los funcionarios públicos nos llevaría a la defensa y salvaguarda de los derechos, como por ejemplo el correcto policía que sanciona al conductor que intenta pasar una luz roja y así evita que atropelle y mate a una persona, cumpliendo así con proteger el derecho a la vida. Cf. RIDALL, J.G. Teoría del derecho. Barcelona: Gedisa, 1991, pp. 149-165.

¿CONSTITUCIONALIZAR EL DERECHO O POLITIZAR LA CONSTITUCIÓN? AMENAZAS, RIESGOSY PELIGROS EN EL CONSTITUCIONALISMO CONTEMPORÁNEO

CONSTITUTIONA-

LIZETHE LAW OR POLITICIZETHE CONSTITUTION? THREATS, RISKS AND DANGERS IN CONTEMPORARY CONSTITUTIONALISM 
constitucionalización corresponde a un proceso en el que claramente se aprecia una constitución visible en todos los ámbitos, es decir — como acota ahora el profesor Guastini — una Constitución invasiva del Derecho que «condiciona la legislación, la jurisprudencia, la doctrina y los comportamientos de los actores políticos» ${ }^{12}$. En este sentido, se ha producido un cambio en la concepción del derecho, pues el estatalismo, el legicentrismo y el formalismo interpretativo propios de la tradición positivista están siendo reemplazados por una Constitución basada en principios liberales y que son empleados - los principiosen la interpretación del derecho. Así pues, el derecho deja de ser un objeto destinado al análisis y la descripción y se convierte en un objeto prescriptivo o normativo, por lo tanto la teoría constitucional toma como objeto de investigación la Constitución como norma ${ }^{13}$.

Cuando se hace referencia al constitucionalismo como ideología (constitucionalismo ideológico), por otra parte, ya no se considera como esencial el establecer límites o controles al Estado sino que lo que se prioriza es la salvaguarda y garantía de los derechos fundamentales, buscando incluso su ampliación. Así —como observaremos luego con detalle-, el constitucionalismo contemporáneo en general afirma la tesis de la vinculación necesaria entre el derecho y la moral; entonces, los constitucionalistas ideológicos consideran que es una obligación moral obedecer la Constitución, porque los principios que se encuentran en ella encarnan la justicia. De esta manera, como en el positivismo ideológico se asociaba a la ley con la justicia y por ende se establecía la obligación moral de obedecer a la Constitución, entonces el neoconstitucionalismo ideológico ${ }^{14}$ establece el mandato definitivo de cumplir lo que la Constitución ordene.

12 GUASTINI, Riccardo. «La constitucionalización del ordenamiento jurídico: el caso italiano». En Miguel CARBOnell (ed.). Ob. cit., p. 49. De hecho, Guastini indica siete condiciones que debe satisfacer un ordenamiento para que sea considerado como "constitucionalizado». Entre estas destacan: 1. La Constitución rígida (Constitución escrita y protegida contra la legislación ordinaria). 2. La garantía jurisdiccional de la Constitución (es decir, la existencia de un control de constitucionalidad a cargo de un juez o de un órgano especializado). 3. La fuerza vinculante de la Constitución sustentada fundamentalmente en principios generales. 4. La sobreinterpretación de la Constitución, que considera no una interpretación literal sino una interpretación extensiva, es decir, que cabría la posibilidad de extraer normas implícitas. 5. La aplicación directa de las normas constitucionales, es decir, considerar que las normas constitucionales deben ser tomadas como reglas de aplicación inmediata. 6. La interpretación conforme de las leyes: se tiende ahora a considerar que toda interpretación de la ley debe guardar plena armonía con la Constitución. 7. La influencia de la Constitución sobre las relaciones políticas (los órganos y actores políticos suelen emplear las normas constitucionales para justificar sus acciones y sus decisiones. Finalmente, Guastini añadirá que la constitucionalización es una cuestión de graduación, dependiendo del desarrollo de las presentes condiciones (pp. 50,58).

13 Dice al respecto Comanducci que el constitucionalismo teórico puede adoptar como objeto de investigación el modelo descriptivo de la Constitución como norma o el modelo axiológico de la Constitución como norma. En el primer caso se trata de reconocer en la Constitución a un conjunto de reglas positivas que respecto de otras reglas son de carácter superior; en el segundo caso, igual la Constitución es un conjunto de reglas positivas fundamentales con respecto a otras, siempre y cuando posean estas un valor o contenido, es decir, que la Constitución para este modelo posee un valor en sí mismo. Añade finalmente Comanducci que, si se toma el modelo axiológico, el constitucionalismo, más que una teoría, sería una ideología. Ob. cit., p. 84

14 Ibíd., p. 86. 
Finalmente, en relación con el constitucionalismo metodológico o el método de estudio y conocimiento del derecho, este se sustentaría, a diferencia del positivismo, en la tesis de la vinculación necesaria entre el derecho y la moral ${ }^{15}$, es decir, que se puede considerar que cualquier decisión jurídica estaría justificada en tanto derive de una norma moral ${ }^{16}$.

En resumen, entonces, se puede afirmar que el constitucionalismo contemporáneo puede ser concebido principalmente como una nueva teoría del derecho de carácter normativo (a diferencia de la teoría positivista, que era meramente descriptiva) y que mediante el llamado proceso de constitucionalización hace que el derecho se convierta en Constitución o que la Constitución sea el derecho, pero al ser un derecho justificado en normas morales, entonces estará por encima de los legisladores o de cualquier autoridad política, por lo que todos tienen que ceñirse a su mandato. En este contexto, quienes interpretan el derecho — lo que es lo mismo, la Constitución— son los jueces, que en último término pueden efectuar lo que se llamaría una "lectura moral" del derecho. Pero, iqué implica dicha lectura? ${ }^{17}$. Si partimos de que el propio concepto de moral puede ser también interpretado ${ }^{18}$, entonces ipodemos quedar a merced de una arbitrariedad judicial que podría extenderse, dada la indeterminación propia de los principios morales? Y dentro de este contexto, ¿en qué medida el constitucionalismo puede convertirse en un real defensor e impulsor de los valores democráticos y liberales?

Es interesante en todo caso destacar este trasfondo filosófico y político que subyace finalmente dentro de este discurso (y que en realidad subyace a todo discurso jurídico), aunque paulatinamente se ha ido

15 Como ya comentamos en la nota 9, existen distintas lecturas respecto de la relación entre el derecho y la moral, existe la tesis de la separación (positivismo), la de la vinculación necesaria y permanente entre el derecho y la moral (constitucionalismo ideológico) y la conexión contingente (el llamado positivismo incluyente). Sobre este último se puede revisar el texto de Kenneth EINAR, Derecho y moral: el debate entre el positivismo incluyente y el excluyente. Bogotá: Externado de Colombia, 2011, cap. 1. También, de Wilfrid WaLluchow, Positivismo jurídico incluyente. Madrid: Marcial Pons, 2007, cap. IV.

16 lbíd., p. 94.

17 Dice al respecto el profesor español Rafael ESCUDERO: «En primer término la incorporación de principios y valores abre la puerta a los intentos de manipulación moral por las autoridades competentes, las cuales intentarán legitimar sus decisiones alegando el presunto respeto a un valor moral. Esto resulta especialmente preocupante cuando se trata de jueces constitucionales, dado que sus acciones pueden enmendar y corregir al legislador, quien en las modernas democracias — por lo menos formalmente- es el representante de la soberanía popular. Así, el juez constitucional podría arroparse en el manto de la moral objetiva a la hora de justificar una decisión adoptada sobre la base de las creencias morales de sus miembros». Cf. ESCUDERO ALDAY, Rafael. "La respuesta positivista al desafío del neoconstitucionalismo», p. 116. En Susana Pozzolo (ed.), Neoconstitucionalismo, derecho y derechos. Lima: Palestra, 2011.

18 Por ejemplo, como moral positiva o como moral crítica; la primera afirma que la regla la determina la voluntad (social) y que es cambiante, y la segunda, que la regla se origina en la razón y no varía con el tiempo. Lógicamente que el constitucionalismo - sobre todo el ideológico- se asociará a esta última forma de moral que tiene pretensiones de objetividad. 
desdibujando ${ }^{19}$, pues este fue muy claro cuando la Constitución fue concebida como orden y aún era visible al considerarse a la Constitución como reglas, pero al transformarse la Constitución en derecho, entonces parece desaparecer. La tesis que sostendré aquí será que este alejamiento de la Constitución de la política que se halla en la llamada «constitucionalización» del derecho impedirá asegurar la defensa de los principios liberales y de la democracia. Pasemos a ver ahora cómo se desarrolla este constitucionalismo clásico ligado al orden y a las reglas y que se percibe en los trabajos de los filósofos políticos.

\section{EL CONSTITUCIONALISMO CLÁSICO: EL LIBERALISMO Y LA VIRTUD}

Al hablar de Constitución podemos considerar en realidad un término que viene desde muy antiguo, desde el mundo de la filosofía clásica occidental, en donde la Constitución es en realidad un concepto político que se identifica con el término Politéa, esto es, con la idea de régimen o de forma que adopta la ciudad ${ }^{20}$.

Más bien en tiempos modernos, inicialmente, el llamado Estado Constitucional o Estado de Derecho — siguiendo aquí al ilustre jurista alemán Carl Schmitt- se caracterizó por la defensa del concepto de libertad burguesa, es decir que, a diferencia del Constitucionalismo clásico — por ejemplo la Constitución—, no perseguía el bien común o la gloria del Estado (aun en el caso de Montesquieu, por ejemplo), sino la libertad política de los ciudadanos frente al posible abuso del poder público ${ }^{21}$. En este sentido, se consideraba entonces que no existía un Estado burgués de derecho si es que no había derechos individuales y no se establecía la separación o división del poder: «De la idea fundamental de la libertad burguesa se deducen consecuencias que integran los principios del elemento típico del Estado de Derecho,

19 Sin embargo, llama la atención que los constitucionalistas contemporáneos más bien hagan hincapié en el supuesto trasfondo filosófico político del derecho actual —Ronald Dworkin, por ejemplo— pero desde el punto de vista que manejo en este texto -y que sigue las líneas marcadas por Carl Schmitt y Leo Strauss - los neoconstitucionalistas identifican prácticamente a los derechos con la política, cuando más bien para teóricos como Schmitt los derechos relativizaban lo político, o en el caso de Strauss, la política no solamente consistiría —como pensarían los neoconstitucionalistas- en evitar el mal sino también en hacer el bien. En la tercera parte de este artículo desarrollaré más a fondo ambas ideas.

20 Sin duda el concepto aristotélico de Constitución o politeia es el que se puede asociar con la ciudad antigua y su ideal de orden y de unidad política. Dice al respecto el profesor Maurizio Fioravanti: «Nosotros pensamos, en efecto, que las cosas son más simples de lo que cierta farragosa crítica historiográfica entiende. En pocas palabras, politeia no es más que el instrumento conceptual del que se sirve el pensamiento político del siglo IV para enuclear su problema fundamental: la búsqueda de una forma de gobierno adecuada al presente, tal que refuerce la unidad de la polis, amenazada y en crisis desde distintos frentes. En el ámbito de ese pensamiento, esta búsqueda tiene una palabra que la anima, que le permite expresarse, que es precisamente politeia. Con ella se intenta subrayar la necesidad de penetrar en la forma de la unión política, de manera que tome lo que en el fondo caracteriza la polis, lo que la mantiene unida». FIORAVANTI, Maurizio. Constitución de la antigüedad a nuestros días. Madrid: Trotta, 2011, p. 19.

21 SCHMITT, Carl. Teoría de la Constitución. Madrid: Alianza, 1992, p. 138. 
presente en toda Constitución moderna. Primero, un principio de distribución: la esfera de la libertad del individuo se supone como un dato anterior al Estado, quedando la libertad del individuo ilimitada en principio, mientras que la facultad del Estado para invadirla es limitada en principio. Segundo, un principio de organización que sirve para poner en práctica ese principio de distribución: el poder del Estado (limitado en principio) se divide y se encierra en un sistema de competencias circunscritas $»^{22}$.

Esta concepción del constitucionalismo moderno se plasmó, por ejemplo, en la famosa Declaración de los Derechos del Hombre y el Ciudadano (artículo 16), que afirmaba precisamente que no había Constitución sin derechos fundamentales y sin separación de poderes (también en las Constituciones americanas, como por ejemplo en la Declaración de Virginia de 1776 o también en la Constitución francesa de 1791, entre otras $)^{23}$.

Sin embargo, tampoco hay que perder de vista que, en un sentido no liberal — sostendría también Schmitt-, la Constitución no tenía por qué estar vinculada necesariamente con la libertad burguesa; al contrario, su centro estaría ubicado en la noción de unidad política y la ordenación social. Así, la Constitución no sería otra cosa que el reflejo de la unidad política del Estado ${ }^{24}$. Tal forma de considerar a la Constitución (en un sentido absoluto, en el lenguaje de Schmitt) sería en realidad una forma clásica de concebirla en concordancia con las ideas de los filósofos griegos como Aristóteles, para quien la Constitución, por ejemplo, podía entenderse como la ordenación de la vida en común dada a los hombres de una ciudad ${ }^{25}$. No obstante, como anotaba más arriba, más conocida aún era la identificación del concepto de Constitución antigua con el de régimen político (politeia).

Así pues, en su conocida Política, Aristóteles sostenía que la comunidad política (polis) debía entenderse como una comunidad (koinonia) de ciudadanos (polites) en una constitución (politeia), siendo que la politeia era la forma que hacía que la comunidad política fuese lo que era ${ }^{26}$.

Sin embargo, habría que precisar mejor cuál podría ser el significado más preciso del concepto régimen. Para el conocido filósofo político Leo Strauss, por ejemplo, el régimen es la forma que adopta la ciudad: «el régimen es el orden, la forma que da a una sociedad su carácter.

23 Cf. CARBonelL, Miguel. Una historia de los derechos fundamentales. México: UNAM-PorrúaComisión Nacional de los Derechos Humanos, 2005.

24 Schmitt, Carl. Teoría de la Constitución, p. 30. Como acotaba, también la cita de Fioravanti.

25 Ibíd.

26 TARCOV, Nathan. «Ideas of Constitutionalism. Ancient and Modern». En Steven KAUTZ, Arthur MELZER, Jerry WEINBERGER y M. Richard ZINMAN (eds.). The Supreme Court and the Idea of Constitutionalism. Philadelphia: University of Pennsylvania Press, 2009, p. 16. Cf. Aristóteles. Política, $1276 \mathrm{~b}$. Aristóteles. Política. Madrid: Gredos, 1999.

¿CONSTITUCIONA-

LIZAR EL DERECHO

O POLITIZAR LA

CONSTITUCIÓN?

AMENAZAS,

RIESGOSY

PELIGROS

EN EL CONSTITU-

CIONALISMO

CONTEMPORÁNEO

CONSTITUTIONA-

LIZE THE LAW OR

POLITICIZETHE

CONSTITUTION?

THREATS, RISKS

AND DANGERS IN

CONTEMPORARY

CONSTITUTIONA-

LISM 
Es, por tanto, un modo específico de vida. El régimen es la forma de vida de convivencia, el modo de vida de la sociedad y en la sociedad $»^{27}$. De este modo, el régimen le daría el sentido (telos) a la comunidad, pudiendo ser el caso de que existan distintos fines y en concordancia distintos regímenes o constituciones. "La estructura o forma de un régimen nos permite acceder al telos del régimen. Diferentes regímenes tendrán entonces distintas formas, y a causa de sus diferentes formas, ellos tendrán distintos fines. Tal diferencia de fines los llevará a sostener variadas formas autoritativas de vida que llevarán en su momento a diversas concepciones de justicia» ${ }^{28}$.

De esta manera, para Aristóteles la Constitución (régimen) era mucho más fundamental que las leyes, no en tanto la máxima ley, sino en tanto el fundamento que moldeaba el resto de leyes ${ }^{29}$. En esta línea, se podía afirmar que la tarea de la filosofía política no era otra que la búsqueda del mejor régimen político ${ }^{30}$. Ahora bien, en tanto existían distintos modos de ser (constituciones) de diferentes colectividades, y estando abierta la posibilidad de que se produzcan conflictos entre ellos, era necesario entonces determinar cuál sería el mejor de todos, de allí la idea de considerar que la labor de los filósofos políticos era determinar cuál sería ese régimen y qué posibilidades reales habría de su concreción ${ }^{31}$.

Dentro de la lectura aristotélica reconocíamos distintos tipos de gobierno, según el número de personas que ejercían el poder, la calidad de estas personas y sus fines. Así, el gobierno de uno a favor del bien común era la monarquía, mientras que su contraparte (el gobierno de aquel que actuaba en favor de su interés personal, en este caso) sería la tiranía; si se trataba de una minoría rica que actuaba a favor del bien de todos, aristocracia, y su contraparte (que actuaba en función a su interés de grupo), la oligarquía. Finalmente, el gobierno de las mayorías pobres a favor de sus intereses era la democracia, mientras que la república (politeia o Constitución) sería el gobierno de todos a favor del bien común $^{32}$.

Justamente esta noción de régimen o Constitución resulta determinante para identificar cuál podría ser considerado finalmente el mejor régimen entre todos los indicados y pueda de este modo ser considerado como

27 STRAUSS, Leo. ¿Qué es filosofía política? Ob. cit., p. 44; también, La ciudad y el hombre. Ob. cit., p. 72. Ciertamente, Strauss no solo señala que el régimen es la forma sino también considera que la materia la constituiría el pueblo o nación, empero, es el régimen el que influencia directamente a la materia y le da su carácter.

28 BATES, Clifford Angell. Aristotles's «best regime». Kinship, democracy and the rule of law. Baton Rouge: Louisiana State University, 2003, p. 62.

29 TARCOV, Nathan. Ob. cit., p. 17

30 StRaUSS, Leo. ¿Qué es filosofía política? Ob. cit., pp. 44-45; La ciudad y el hombre. Ob. cit., p. 33.

31 lbíd., p. 45. Por ejemplo Strauss, siguiendo a los «antiguos», sostiene que la materialización del mejor régimen dependerá de cuestiones que están fuera del control humano, como en el caso del azar.

32 ARIStÓteles. Política, 1279 b 5 -8. 
el régimen constitucional ${ }^{33}$. En este sentido, Aristóteles proponía varias posibles alternativas, empezando por aquello que señalaba como una forma de régimen mixto que se daría a partir de la combinación de dos regímenes considerados independientemente como pervertidos, a saber, la oligarquía y la democracia ${ }^{34}$. Se entendería así que dicho régimen sería el mejor, porque no solo tendría el apoyo de las mayorías sino también de todos los sectores de la población. Es más, si se asumía que la oligarquía (minorías ricas) oprimía y excluía a los pobres y que la democracia (los pobres) excluía y oprimía a los ricos, entonces la Constitución mixta lograría que ambas fuerzas se neutralicen y, por lo tanto, la suma de estos dos regímenes desviados produciría un régimen justo e inclusivo. Tal régimen podría dejar abierta la posibilidad de la virtud, que correspondería al régimen de la aristocracia ${ }^{35}$.

En este sentido, también era posible encontrar en Aristóteles una tercera forma de definir el concepto de Constitución además de las dos anteriores; es decir, la del régimen identificado con el bien común y también la del régimen mixto. Esta correspondería al régimen en el que predominaría la clase media; se destacarían por excelencia las virtudes de dicha clase, que se encontrarían en medio del despotismo que caracteriza a los ricos y la envidia propia de los pobres. De esta forma se podría lograr una mayor integración entre todos ellos, apareciendo entonces como ciudadanos libres e iguales ${ }^{36}$. Finalmente, Aristóteles también aproxima la Constitución al gobierno de la ley, ya que la generalidad de estas últimas, así como su racionalidad, serían mejores que la arbitrariedad y la pasión que podrían acompañar a una decisión particular.

La Constitución, por último, podrá ser mejor preservada si cuenta con el respaldo de la educación, es decir, que no se podría conservar el buen régimen político si no se educa a favor de la preservación de la Constitución, permitiendo que los ricos (oligarquía) no sean tan excluyentes con los pobres, y que al mismo tiempo los pobres no discriminen a los ricos (democracia) ${ }^{37}$.

Un aspecto importante en esta lectura y que vale la pena resaltar es que la Constitución antigua y la política no estaba orientada a promover la excelencia humana y el perfeccionamiento de los ciudadanos, cosa que parecería ser más ideal que real. En este sentido, «la tarea primordial de la política en general, según Aristóteles,

33 Además, el mejor régimen tendría que ser aquel que contribuye a que los hombres vivan bien y alcancen el grado de eudaimonia (felicidad) a través de la justicia. Cf. Clifford Angell BATES Jr. Ob. cit., p. 69.

34 ARISTÓteles. Política, 1290b; también cf. Nathan Tarcov. Ob. cit., p. 17

35 TARCOV, Nathan. Ob. cit., p. 18.

36 lbíd.

37 lbíd. 
no es perfeccionar el alma de los hombres sino preservar regímenes reales e imperfectos, fortaleciendo a los ciudadanos contra los malos hábitos y las tendencias destructivas alentadas por el modo de vida al que su régimen está consagrado. La ciencia política aristotélica no procura transformar regímenes imperfectos, como las democracias y las oligarquías, en regímenes consagrados a la excelencia humana, sino que procura instituir medidas que permitan que los regímenes imperfectos respeten sus principios y moderen sus tendencias imprudentes ${ }^{38}$.

Ahora bien, los ecos del constitucionalismo clásico igual podrían ser percibidos en los inicios de la modernidad, a pesar de que esta se presentará como una forma de ruptura con el pasado; sin embargo, sabemos que existieron intentos por retornar al pasado, aunque eso solo sirvió para radicalizar el proyecto de la modernidad ${ }^{39}$. En este sentido, podemos percatarnos, en el desarrollo del republicanismo moderno, de las influencias de la llamada Constitución o régimen mixto, especialmente a través de la lectura propuesta por el historiador griego Polibio (205-123 a.C.), inquieto respecto de la expansión romana y buscando conocer la causa de ella. Siguiendo esta línea, Cicerón (106-43 a.C.) consideraba que en dicho régimen «los magistrados tienen poder suficiente, los consejos de los ciudadanos notables tienen influencia suficiente, y el pueblo tiene libertad suficiente» ${ }^{40}$. La propuesta de la Constitución mixta sería tomada también de manera casi literal por Maquiavelo en los Discursos sobre la primera década de Tito Livio, así como también se podría apreciar en los trabajos de filósofos modernos como Bodin y Hobbes ${ }^{41}$, y por último, también en el republicanismo de Monstesquieu o en los Papeles del federalista vía la influencia del republicanismo maquiavélico ${ }^{42}$.

$\mathrm{Al}$ evaluarse algunas de las características de este constitucionalismo antiguo, nos damos cuenta de las grandes distancias que existen con el constitucionalismo contemporáneo. ¿Cómo explicar esta situación? Precisamente uno de los intereses que tengo está en principio en identificar el carácter ideológico del actual constitucionalismo, lo cual resulta lógico si consideramos que la filosofía política antigua que dio el sustento al constitucionalismo clásico ha sido reemplazada hoy en día por la ideología ${ }^{43}$. Es decir, ahora se consideraría que la tarea

38 Berkowitz, Peter. El liberalismo y la virtud. Santiago de Chile: Andrés Bello, 2001, pp. 31-32.

39 TARCOV, Nathan y Thomas L. PANGLE. «Epílogo, Leo Strauss y la historia de la filosofía política». En Leo Strauss y Joseph Cropsey (comps.). Historia de la filosofía política. México: FCE, 1993, p. 863. Cf. Leo Strauss, "The three waves of modernity». En Hilaial Gildin (ed.). An Introduction to Political Philosophy. Ten essays by Leo Strauss. Detroit, Michigan: Wayne State University Press, 1975. 40 Cicerón, De República, II 57- 58.

41 MANIN, Bernard. Los principios del gobierno representativo. Madrid: Alianza, 1998, p. 63.

42 RAHE, Paul A. Montesquieu and the Logic of Liberty. New Haven: Yale University Press, 2009. Respecto de la influencia de Maquiavelo en el constitucionalismo americano, se puede ver el clásico texto de John Pocock, El momento maquiavélico, el pensamiento político florentino y la tradición republicana atlántica. Madrid: Tecnos, 2002.

43 Strauss, Leo. La ciudad y el hombre. Ob. cit., introducción, p. 10. 
de la filosofía política moderna debía ser la de orientar al hombre a la conquista de la naturaleza, siendo que la ciencia debía ser la de guiarnos hacia un progreso ilimitado y, además, de proporciones universales. Es decir, se trataría de que todos los seres humanos fuesen incluidos dentro de una suerte de Estado universal en un único régimen que sería igual para todos, gozándose así de amplias libertades y de igualdad ${ }^{44}$. Claro que esto sería básicamente una visión del mundo (ideología) que se concretaría «aquí y ahora» y que excluiría ya la idea de la pluralidad de regímenes y de la búsqueda del mejor de ellos. Esto sería reemplazado por el único régimen posible y deseable, a saber, «el constitucionalismo democrático» ${ }^{45}$, según interpretan los llamados neoconstitucionalistas.

No obstante lo dicho, pienso que el desarrollo del constitucionalismo moderno ha sido paulatino (hasta llegar ahora a la forma de neoconstitucionalismo), en la medida en que todavía podía percibirse entre los autores liberales de los siglos XVIII y XIX cierta influencia de la filosofía política clásica (aristotélica), orientada, como indiqué, a la búsqueda del mejor régimen posible. Esto precisamente por la relación aún cercana con el pasado y la filosofía antigua ${ }^{46}$. En este sentido, cabría retornar ahora a aquello que ya mencioné respecto del constitucionalismo moderno y su identificación con los derechos individuales y con la separación de poderes. Precisamente este último punto resulta muy significativo, ya que nos conduce hacia la dimensión política del constitucionalismo y que mantiene ese nexo con el constitucionalismo clásico: su relación con el concepto de régimen político, en este caso la democracia.

Así, un importante filósofo político francés como Pierre Manent asocia a esta (la democracia) con la tesis de la separación de poderes: «la democracia es una organización de separaciones» ${ }^{47}$. En realidad $-\mathrm{y}$ parafraseando a Ferguson-, el siglo XVIII sería considerado como «el siglo de las separaciones» (age of separations), encontrándose entre otras la separación Iglesia y Estado, la separación representante y representado, la separación hecho y valor, y por supuesto, lo que nos interesa aquí: la separación de poderes ${ }^{48}$.

44 lbíd., pp. 15-16. Ver también en este sentido las ideas de un autor como Luigi Ferrajoli, autodenominado positivista crítico, pero en realidad más cercano al constitucionalismo ideológico y su propuesta de constitucionalismo globalizado. FERRAJOLI, Luigi. Razones jurídicas del pacifismo. Madrid: Trotta, 2004; Principia luris. 3 vols. Madrid: Trotta, 2011. Para una crítica muy interesante respecto de esta opción. Cf. Eric A. Posner. The Perils of Global Legalism. Chicago: Chicago University Press, 2009.

45 Esta sería también una variante del discurso socialdemócrata, que parece ser la base ideológica del neoconstitucionalismo. Cf. Rodolfo VÁZQUEZ. Consenso socialdemócrata y constitucionalismo. México: Fontamara, 2012.

46 Por ejemplo, ver el texto de Peter BERKowitz. El liberalismo y la virtud. También Leo STRAUSS, El liberalismo antiguo y moderno. Buenos Aires: Katz, 2007.

47 Manent, Pierre. Curso de Filosofía Política. México: FCE, 2003, p. 21.

48 Ibíd.

¿CONSTITUCIONA-

LIZAR EL DERECHO

O POLITIZAR LA

CONSTITUCIÓN?

AMENAZAS,

RIESGOSY

PELIGROS

EN EL CONSTITU-

CIONALISMO

CONTEMPORÁNEO

CONSTITUTIONA-

LIZE THE LAW OR

POLITICIZETHE

CONSTITUTION?

THREATS, RISKS

AND DANGERS IN

CONTEMPORARY

CONSTITUTIONA-

LISM 
En principio, se podría señalar que estas separaciones se orientan a generar y a mantener la libertad moderna. Si bien es cierto que en el mundo antiguo existía la distinción o separación que permitía identificar quiénes eran los que mandaban y quiénes obedecían ${ }^{49}$ (es decir, para afirmar la jerarquía), esto se hacía más bien para evitar confusiones en los roles y, de esta manera, mantener la unidad política, que era lo más importante, como ya vimos. En el caso de la modernidad, más bien, esta separación ${ }^{50}$ se orienta en otro sentido, ya que buscaría en todo caso abolir las jerarquías a través de la figura de la representación ${ }^{51}$, pero a su vez para evitar que la representación pueda restablecer la distinción mando-obediencia. Así, se planteó una segunda distinción que defendería el constitucionalismo de la modernidad: la separación de poderes.

Así pues, el constitucionalismo del Estado burgués de derecho (en términos citados por Schmitt) se adhirió a la tesis de Montesquieu tomando como modelo el sistema político inglés, que buscaba evitar la concentración del poder, sea en el ejecutivo o en el legislativo, a partir del balance y considerando finalmente que, si se trataba de que un poder quisiera avasallar al otro, el pueblo se volcaría a favor del más débil y así se restablecería el equilibrio, garantizándose las libertades. Pero este sistema fue rápidamente reemplazado en Inglaterra por el gobierno de gabinete, donde se integraban el ejecutivo y el legislativo ${ }^{52}$, aunque sin abandonar la defensa de la libertad moderna. En este caso, la separación se trasladaba a otro ámbito, que sería ahora el de la distinción mayoría y oposición. Finalmente, con esta distinción se podría afirmar que, respecto del tema de las «separaciones», no solo resultaba relevante el aspecto de la libertad individual entendida por los modernos, sino que en último término se podía considerar vinculada con la libertad de los antiguos, que estaba más orientada al tema del autogobierno republicano ${ }^{53}$.

Según esta concepción, entonces, el constitucionalismo mantendría aún su nexo con el clasicismo, ya que se trata de plasmar una forma de gobierno a través de la relación mayoría y minoría. Eso ocurrió con el caso de la Constitución de los Estados Unidos, por ejemplo, con su fórmula orientada a moderar las relaciones entre los muchos y los

49 lbíd., p. 23.

50 Propuesta fundamentalmente por MONTESQUIEU, Cf. El espíritu de las leyes. Cap. VI del libro XI

51 MANENT, Pierre. Ob. cit., p. 24.

52 BAGEHOT, Walter. La Constitución inglesa. Madrid: Centro de Estudios Políticos y Constitucionales, 2010.

53 Evidentemente la relación entre libertad y autogobierno corresponde al concepto de libertad de los antiguos expresado por Benjamin Constant, y asociada con la deliberación pública, votar las leyes, sentenciar, examinar cuentas; en cambio, la libertad de los modernos se vinculaba con el hecho de no estar sometido sino solo a la ley, en el derecho de no ser detenido, ni maltratado, el derecho de decir su opinión, entre otros. Cf. Benjamin CONSTANT, «De la libertad de los antiguos». En Del espíritu de conquista. Madrid: Tecnos, 1988. 
$\operatorname{pocos}^{54}$, evitando que las mayorías sometan a las minorías, pero también otorgándoles a estas últimas un poder contra las mayorías (checks and balances). Esto nos haría recordar el carácter republicano aún presente en el constitucionalismo moderno, buscando conformar finalmente aunque dentro del lenguaje de la modernidad - un sistema político constituido por un sistema de partidos como reflejo de la unidad política y del compromiso ciudadano con la marcha de la ciudad y la búsqueda de su bienestar y, por lo tanto, enfatizando las obligaciones políticas antes que los derechos individuales.

\section{LA MORALIZACIÓN DE LA CONSTITUCIÓN Y LA AMENAZA A LOS VALORES LIBERALES Y DEMOCRÁTICOS}

Si por democracia vamos a entender ahora la participación activa en la toma de decisiones de los ciudadanos (de todos como en una república) y por constitucionalismo o neoconstitucionalismo identificaremos a la Constitución moralizada —en el discurso de los derechos individuales-, entonces voy a tratar de mostrar - y aquí siguiendo a Carl Schmitt- que esta moralización de la Constitución genera un problema concreto, a saber, la despolitización del derecho y la Constitución. Al darse esta situación, entonces se va a tener paradójicamente un problema en el sentido de no poder afirmar los valores que supuestamente el neoconstitucionalismo dice defender, como la libertad, la igualdad o el pluralismo. En este sentido, considero en principio que el constitucionalismo de los derechos desincentiva la participación política e impide el desarrollo de la ciudadanía, que se educa precisamente con el conocimiento y la práctica política en un derecho de jueces, como propone el neoconstitucionalismo. Entonces, se empieza a excluir a la ciudadanía de la toma de decisiones y se mediatiza su fuerza al momento que la legislación queda a merced del control de constitucionalidad o, en el mejor de los casos, la legislación queda para decisiones menudas y sin mayor trascendencia.

Por su parte, el neoconstitucionalismo, al adoptar después de la Segunda Guerra Mundial un lenguaje moral en el derecho (la deontología kantiana), deja de lado el sentido político propio de la constitución clásica y aun de la moderna (como vimos en el primer capítulo), que consideraba a la Constitución como el producto de una «ciencia política» o conocimiento político (Cf. Los papeles del federalista, fundamento de la Constitución estadounidense). Ahora la Constitución no considera relevante el conocimiento de la naturaleza humana, las características de la población o el espacio territorial, sino que afirma 
un texto sustentado en una moral crítica (la kantiana) y de allí impone sus condiciones en abstracto. Tal moral, como es sabido, se sostiene en el llamado consenso sobre el mal y el disenso sobre el bien, por lo que la Constitución técnicamente te dice qué cosas no debes hacer pero no te señala las que debes realizar (que sería precisamente lo que se espera también de la política, es decir, que indique las medidas a ejecutar).

Pero, icómo se genera está despolitización y moralización de la Constitución? Según el profesor Schmitt ${ }^{55}$, y más recientemente Richard Bellamy ${ }^{56}$, el liberalismo moderno, al enfatizar en el individualismo, comienza a afectar a lo político al relativizarlo. Esto precisamente porque lo político se refiere a lo colectivo, a la relación entre las mayorías y las minorías, pero el individualismo ya no reconoce mayorías o minorías o la unidad política, sino solamente el individuo atomizado pero dotado de un enorme poder a través de los derechos individuales.

Sin embargo, el neoconstitucionalismo no solamente es heredero del liberalismo moderno, sino también lo es del socialismo. El socialismo (gestado desde las fuentes marxistas), al ser una ideología sustentada en la búsqueda de la igualdad, se ponía inmediatamente del lado de los «vulnerables» o desposeídos que, según el contexto, podían ser mayorías o minorías, pero siempre eran calificados como los excluidos o los despojados o abusados.

Ciertamente la lectura socialista, al igual que esta lectura liberal contemporánea, no podía ser calificada tampoco como política en sentido estricto, pues aquí se tomaba partido no por la totalidad de la comunidad, por la unidad política (que era lo esencial en el pensamiento constitucional clásico), sino por la mayoría (oprimida por la minoría) o por la minoría (ahora sometida por la mayoría). Es decir, siguiendo la ideología marxista, siempre existiría un sujeto (mayoría o minoría) dotado de poder, y la otra parte (iobjeto?) que carecería totalmente de poder, por lo que sería siempre dominada.

Respecto de este último punto se podrían ya empezar a tejer lazos entre el constitucionalismo contemporáneo y el socialismo, en el sentido de que dicha corriente asocia fundamentalmente los derechos con los desvalidos o vulnerables ${ }^{57}$, como diría el fallecido profesor Dworkin, los derechos como triunfos de las minorías para evitar que las preferencias

55 ScHmITT, Carl. El concepto de lo político. Madrid: Alianza, 1991, p. 97.

56 BelLAMY, Richard. Constitucionalismo político, una defensa republicana de la constitucionalidad de la democracia. Madrid: Marcial Pons, 2010. La tesis de Bellamy se orienta hacia el Constitucionalismo republicano, en donde la Constitución es el marco para que se desarrolle el autogobierno. De esta forma, dice el profesor Bellamy, «la cualidad clave que los republicanos persiguen es que el proceso político obligue a aquellos que toman las decisiones a escuchar a la otra parte», p. 193.

57 Por ejemplo, FerRAJoli, Luigi. Derecho y garantías, la ley del más débil. Madrid: Trotta, 2006 o DWORKIN, Ronald en sus textos ya citados, Los derechos en serio, El imperio de la justicia o Una cuestión de principios, entre otros. 
de las mayorías le sean impuesta ${ }^{58}$, y asimismo se va estructurando la tesis de la neutralidad que debe tener el Estado frente a las preferencias personales de los ciudadanos ${ }^{59}$.

De esta manera, la tesis de la neutralidad se convierte en una grave amenaza para la existencia de una sociedad plural (base de una sociedad libre). Por ejemplo, cuando el neoconstitucionalismo amparado en la idea de la neutralidad señala que en los espacios públicos deben dejarse de lado símbolos religiosos porque ofenden a los no creyentes, en realidad tal conducta no se es neutral en sentido estricto, pues se toma partido por la secularización y de alguna manera por el ateísmo, apostándose finalmente por una sociedad de no creyentes, lo cual podría alejarnos de la sociedad plural ${ }^{60}$. En otro sentido, la neutralidad liberal y la protección de las minorías, al promocionar las uniones de personas del mismo sexo, también «contribuyen» a deslegitimar los matrimonios heterosexuales y la familia tradicional, siendo esta última anticuada y desfasada frente a las nuevas formas de unión y de «familias». En consecuencia, el pluralismo y la tolerancia frente a las formas tradicionales tiende a desaparecer, y por otro lado, este favoritismo del neoconstitucionalismo y de los medios de comunicación en favor de las «minorías» contribuye seriamente a debilitar la unidad política y a generar conflictos internos ${ }^{61}$.

Para finalizar, dije en principio que el liberalismo contemporáneo es el punto de partida del neoconstitucionalismo; sin embargo, luego anoté que el socialismo es su complemento (io fin?). De esta manera, si juntamos liberalismo y socialismo obtenemos socialdemocracia ${ }^{62}$, es decir, un liberalismo igualitario que sería el componente ideológico que subyace al neoconstitucionalismo y que me llevaría a calificar a este como un neoconstitucionalismo ideológico al fin y al cabo, a pesar

58 DWORKIN, Ronald. «El liberalismo». En Liberalismo, Constitución y democracia. Buenos Aires: La Isla de la Luna, 2003.

59 Ibíd. «¿Qué significa para el gobierno tratar a sus ciudadanos como iguales? [...] Esta pregunta debe ser contestada de dos maneras esencialmente diferentes. La primera supone que el gobierno debe ser neutral en relación con lo que podamos denominar la cuestión de la vida buena. La segunda supone que el gobierno no puede ser neutral en relación con esa cuestión, porque no se puede tratar a sus ciudadanos como seres humanos iguales sin una teoría sobre lo que deben ser los seres humanos» (p. 23). Obviamente que la respuesta que considera Dworkin correcta es la primera.

60 Se puede citar el conocido caso de Nadia Eweira, una cristiana copta que fue despedida por la empresa British Airways al negarse a quitar el crucifijo que llevaba consigo cuando atendía a los clientes. Sin embargo, hay que reconocer que el Tribunal Europeo de los Derechos Humanos al final le dio la razón a ella, lo cual corrobora también algo que parece claro: no todos los jueces son o tienen que ser neoconstitucionalistas.

61 Recientemente en Francia la aprobación del matrimonio gay generó una fuerte reacción en los sectores conservadores, con grandes movilizaciones. De esta manera, estas medidas en favor de estos grupos intensifica las separaciones y los antagonismos.

62 Por ejemplo, se habla ahora del consenso socialdemócrata propio a toda sociedad «decente» y que se expresaría en el Estado constitucional de derecho, orientado a promocionar los derechos sociales, la laicidad, los derechos de las minorías entre otros. Cf. VÁZQUEZ, Rodolfo. Consenso socialdemócrata y constitucionalismo. México: Fontamara, 2012.

¿CONSTITUCIONALIZAR EL DERECHO O POLITIZAR LA CONSTITUCIÓN? AMENAZAS,

RIESGOSY

PELIGROS

EN EL CONSTITU-

CIONALISMO

CONTEMPORÁNEO

CONSTITUTIONA-

LIZE THE LAW OR

POLITICIZETHE

CONSTITUTION?

THREATS, RISKS

AND DANGERS IN

CONTEMPORARY CONSTITUTIONA-

LISM 
de las respuestas en contra de sus promotores, que siempre aluden a un mínimo moral o la posibilidad de hablar de ética sin verdad ${ }^{63}$.

De esta manera, es el componente ideológico y no político (en el sentido original o clásico del término) el que considero que representa el principal peligro del neoconstitucionalismo, alejándonos del pluralismo y paradójicamente restringiendo los márgenes de libertad y autonomía personal.

\section{CONCLUSIONES}

- La Constitución surge como un texto político amparado en el conocimiento político; aquí lo político antecede a lo jurídico.

- El constitucionalismo contemporáneo no asume que la Constitución sea un texto político ni exactamente jurídico, sino moral e ideológico.

- Al ser un texto moral, no puede contribuir al desarrollo de la democracia y del propio liberalismo, porque estos son en el fondo conceptos políticos y jurídicos. Al ser exclusivamente moral (y ojo que la moral kantiana actúa de forma negativa), no puede proteger ni alentar la práctica democrática ni defender una sociedad plural y tolerante.

- Por politizar la Constitución, entiendo devolverle su origen y carácter político y jurídico dejando de lado la moral (kantiana).

- El neoconstitucionalismo es, ideológicamente hablando, socialdemocracia, fruto de la integración entre el liberalismo kantiano y el socialismo.

63 SCARPELLI, Umberto. Ética jurídica sin verdad. México: Fontamara, 2007. En nuestro medio, un difusor de las tesis de Scarpelli es el profesor Félix MORALES. Cf. La Filosofía del derecho de Umberto Scarpelli, análisis del lenguaje y positivismo jurídico. Tesis de doctorado, Universidad de Alicante, 2008. 